17.1

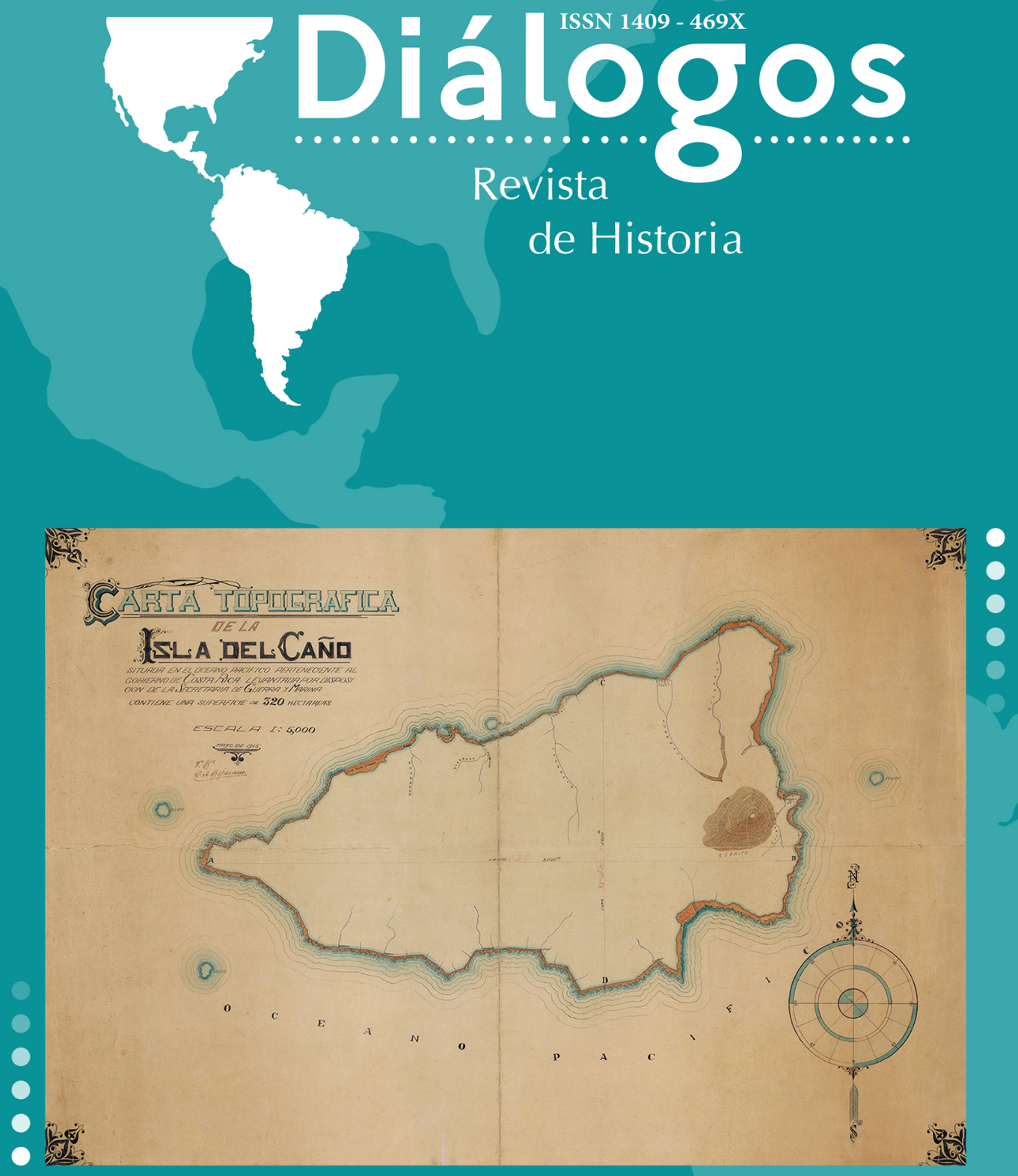

Escuela de Historia. Universidad de Costa Rica

Enero-junio 2016

url: http://revistas.ucr.ac.cr/index.php/dialogos/index 


\title{
JUEGOS DE MIRADAS: ENTRE VOCES HEGEMÓNICAS Y SUBALTERIDADES. ANÁLISIS DEL CUENTO "EL CLIS DE SOL” Y LA CRÓNICA VIAJERA "SAN JOSÉ”"
}

\author{
Mónica Brenes Montoya \\ Larissa Castillo Rodríguez
}

\begin{abstract}
Resumen
El artículo propone un análisis crítico de los textos "El clis de sol", de Manuel González Zeledón, Magón, y "San José”, del libro Vacaciones en Costa Rica de Thomas Francis Meagher, traducido por Ricardo Fernández Guardia. Este análisis se realiza a partir de elementos como la cultura popular, la hegemonía y la subalteridad. El artículo se compone de cuatro apartados. El primer apartado reúne algunas consideraciones iniciales. El segundo apartado, "Literatura como fuente primaria: características, discusiones y sentidos históricos", expone las principales características de las fuentes primarias utilizadas, las discusiones en torno a ellas y el sentido histórico que encierran. El tercer apartado, "Voces, espacios y culturas populares", analiza las voces hegemónicas y subalternas que aparecen en los textos, así como los espacios en tensión que se evidencian en los textos. Finalmente, el cuarto apartado, "Balance final", discute las consideraciones finales, guiándose por las posibilidades de plantear estudios históricos a partir de estos textos y otras fuentes.
\end{abstract}

Palabras claves: hegemonía, subalteridad, cultura popular, literatura, Costa Rica, siglo XIX.

\section{GAZE GAMES, AMONG HEGEMONIC VOICES AND SUBALTERNITIES. ANALYSIS OF THE STORY: "EL CLIS DE SOL” AND THE TRAVEL JOURNAL “SAN JOSÉ”}

\begin{abstract}
The paper proposes a critical analysis of the texts, "El clis de sol" from Manuel González Zeledón, Magón, and "San José" from the book Vacaciones en Costa Rica from Thomas Francis Meagher, translated by Ricardo Fernández Guardia. This analysis is performed based on elements such as popular culture, hegemony and subalternity. The paper is structured in four sections. The first section collects some initial considerations. The second section, "Literature as primary source: features, discussions and historical senses", describes the main features of the primary sources utilized, the discussions around them and the historical sense that they contain. The third section, "Voices, spaces and popular cultures", analyzes the hegemonic and subaltern voices which appear in the texts, as well as the spaces under tension that are evident in the texts. Finally, the four section, "Final Balance", discusses the final considerations, guided by the opportunities to contemplate historical studies from these texts and other sources.
\end{abstract}

Keywords: hegemony, subalternity, popular culture, literature, Costa Rica, century XIX.

Fecha de recepción: 24 de marzo de 2015 • Fecha de aceptación: 27 de julio de 2015

- Mónica Brenes Montoya - Licenciada en Psicología por la Universidad de Costa

- Rica. Docente e investigadora de la Universidad de Costa Rica. Estudiante de la

- Maestría Académica en Historia de la Universidad de Costa Rica. Correo electrónico:

- mobm17@gmail.com

- Larissa Castillo Rodríguez • Licenciada en Filología por la Universidad de Costa Rica.

- Docente en el Instituto Tecnológico de Costa Rica. Egresada de la Maestría Académica

- en Historia de la Universidad de Costa Rica. Correo electrónico: laricastillo@gmail.com 


\section{ALGUNAS CONSIDERACIONES INICIALES}

El comercio del café, hacia la segunda mitad del siglo XIX, supuso una actividad capitalista que convirtió a la agricultura costarricense en un negocio de índole privado que requería de mano de obra asalariada. Esta actividad económica introdujo cambios significativos en las relaciones sociales en Costa Rica: el acaudalado colonialista durante este siglo pasó a ser el oligarca poderoso; mientras que el aldeano agricultor sufrió las consecuencias de subyugarse al nuevo amo cafetalero. No obstante, estos cambios no introducen modificaciones relevantes en los esquemas culturales. Por ejemplo, las producciones literarias o cercanas a lo literario aparecen a fines de la segunda mitad del siglo XIX, con el proyecto de los liberales de construir un discurso nacional oligárquico cuyo objetivo sería consolidar su posición como clase hegemónica en la República.

Es, entonces, hasta finales del siglo XIX que se producen variaciones en los estilos de vida de los ciudadanos privilegiados. Las puertas abiertas por la producción cafetalera traen consigo la inserción del país en el mercado mundial, lo cual modifica las formas de sociabilidad y entretenimiento de las clases hegemónicas. Es aquí donde la literatura comienza a divulgarse en manos de la clase hegemónica, única clase social letrada.

En este contexto, emerge un tipo de relatos vinculados con las exploraciones de viajeros extranjeros, particularmente provenientes de Europa y Estados Unidos, quienes describen sus experiencias en tierras centroamericanas. Aunque los intereses que motivaron a estas personas a desplazarse, particularmente a Costa Rica, son múltiples, se pueden señalar exploraciones económicas, políticas, biológicas, poblacionales, entre otras (Soto-Quirós, 2013a):

\footnotetext{
Cientos de viajeros europeos y estadounidenses recorrieron América Latina en el siglo XIX... y dejaron una vasta producción bibliográfica. Los relatos de viajeros estuvieron motivados por el interés de dar a conocer a un público europeo o estadounidense, las posibilidades que la región ofrecía para la inversión de capital, la apertura de nuevos mercados, fomentar la inmigración como parte de las expediciones científicas o misioneras, o simples relatos de viaje inspirados por la aventura. (Quesada, 2011, p. 14).
}

Según Soto-Quirós, para el caso costarricense "los relatos de viajeros [fueron] fuente de referencia para los intelectuales costarricenses desde finales del siglo XIX, con el objetivo de contribuir al autoelogio de esa "excepcionalidad" nacional" (2013b, párr. 17).

El presente trabajo tiene como objetivo analizar las relaciones entre actores hegemónicos y subalternos; comprender las tensiones de los vínculos sociales, en un momento de profunda transformación económica, social y cultural, así como contraponer las diferentes aproximaciones a estas dinámicas a través de dos producciones literarias.

Las fuentes primarias utilizadas presentan diferencias significativas entre sí; una es el relato de viaje de finales del siglo XIX "San José”, del libro Vacaciones en 
Costa Rica de Thomas Francis Meagher, traducido por Ricardo Fernández Guardia. La otra fuente primaria es un cuento, "El clis de sol" de Manuel González Zeledón, Magón, publicado en 1871. Estas fuentes no solo se diferencian por el género literario al que pertenecen, sino sobre todo, por sus escritores. El primero de origen estadounidense, un viajero cuyas intenciones no son claras, mientras que el segundo es un representante de la oligarquía costarricense.

Son justamente las diferencias entre las fuentes primarias, las que permiten aproximarse de una forma más diversa a las características de las relaciones entre los grupos hegemónicos y subalternos en Costa Rica, de finales del siglo XIX. Es decir, los diferentes espacios desde los cuales los escritores producen sus textos, dan cuenta de distintas formas de vinculación, de tensiones entre los pobladores de un San José que empieza a cambiar por las dinámicas económicas que lo introducen al mercado internacional y que modifican la cotidianidad de sus pobladores.

En este sentido, la principal contribución de este trabajo consiste en profundizar en los aportes que este tipo de fuentes ofrecen al quehacer particular de la historia, y, en términos generales, de las ciencias sociales, como ya lo han evidenciado otros autores. ${ }^{2}$ Las diferencias entre las fuentes primarias señaladas anteriormente, pero también sus similitudes, permiten triangular la información brindada entre ellas y a la vez contrastarla con fuentes secundarias, que faciliten la construcción de una interpretación de los textos a partir de los objetivos del artículo.

\section{LITERATURA COMO FUENTE PRIMARIA: CARACTERÍSTICAS, DISCUSIONES Y SENTIDOS HISTÓRICOS}

Si bien es cierto, los dos textos abordados en este artículo no responden a categorías literarias similares, ambos comparten un mismo periodo y abordan aspectos comunes a la situación socio-histórica de la época (segunda mitad del siglo XIX). Estos textos además de haber sido escritos por personas de la clase hegemónica, plantean cuestiones particulares propias del comportamiento, costumbres e inclusive, complicidades de las clases subalternas, dejando en entredicho la imposición de "reglas o normas" que implícitamente se encuentran en el imaginario de los narradores.

Asimismo, mediante la narración de actividades propias del quehacer cotidiano en Costa Rica, de la representación de las voces dominantes y subalternas y de la exposición de las prácticas populares frente a la consolidada práctica oficial, ambos textos sirven para comprender las intenciones pretendidas por los grupos de poder.

El uso de estos textos como "El clis de sol" y "San José" hace necesario plantear la discusión sobre la pertinencia de utilizar literatura como fuente primaria en la investigación histórica. Algunas posturas alegan que al tratarse de textos creados a partir de la ficción no constituyen una fuente válida para la investigación histórica, de esta forma: 
Refutan la literatura como fuente, al considerar que no hay forma de diferenciar la "realidad histórica" de la narrativa literaria, y reducen el valor de la literatura meramente a ilustrar lo que ya es conocido. También, objetan la literatura como fuente por no poder verificarse con textos específicos. Finalmente, arguyen que tanto los poemas, novelas como la dramaturgia son producto de convenciones literarias. (Fumero, 2003, párr. 13).

Según Patricia Fumero, esta postura encuentra gran oposición, sobre todo a partir de la crítica a la "concepción de una "verdad" histórica anclada en la convicción de que se puede representar la realidad en forma "objetiva," "verídica" y lineal" (Fumero, 2003, párr. 2). A partir de esta crítica, se señala que ni la realidad ni la verdad pueden ser accedidas de forma directa y, por tanto, los textos literarios son el resultado de procesos culturales (Fumero, 2003), que pueden ser analizados a través de la relación entre la producción y los procesos sociales (Alvarenga, 2003).

En referencia al trabajo de Foucault, María Amoretti plantea una reflexión sobre los vínculos entre la historia y la literatura:

\begin{abstract}
Es, en mucho, por la obra de Foucault que nos enfrentamos ahora a un discurso histórico menos solemne y más atento a escuchar el rumor social, como también a una literatura que no tiene ningún complejo en reclamar su función y su vocación historiográfica... Mientras el escritor costumbrista se armaba de los protocolos propios de la historia para aparentar que no fabulaba, el historiador de nuevo cuño se preocupa de aderezar sabrosamente su relato con detalles triviales de la vida cotidiana y títulos sugerentes que amortigüen el carácter adusto de la memoria científica. (Amoretti, 2000, pp. 28-29).
\end{abstract}

Según Amoretti, la literatura es una fuente primaria clave para la historia, pues en ella se puede descubrir a la sociedad no como contenido, sino como discurso; en ella se pueden develar los elementos éticos de la sociedad en que el texto fue producido. En sus palabras, en los textos emerge "el sentido ético sobre el que se construye el universo del texto" (Amoretti, 2000, p. 35).

Antes de analizar el sentido ético, es necesario hacer referencia a trabajos previos en historia que han estudiado la literatura como fuente primaria. ${ }^{3}$ Específicamente sobre las crónicas de viajes, podemos mencionar, entre otros estudios, el trabajo de Ofelia Sanou, Florencia Quesada e Ileana Vives (2000), quienes utilizan las crónicas de los viajeros Wilhem Morr (1853) y el polaco Helmuth Polakowsky (1875) para describir la distribución espacial de las aldeas en los márgenes del río Reventazón, la presencia y las actividades económicas (venta de artesanía y mercadería) de población indígena en el mercado de Cartago, la producción de pejibaye, así como las dinámicas de los aserraderos y la presencia de estadounidenses, dedicados a la carpintería en La Angostura. En general, se puede decir que las autoras utilizan estas fuentes, entre otras, como insumo para reconstruir descriptivamente el proceso de colonización del valle de Turrialba y Juan Viñas.

Florencia Quesada (2011) en su trabajo sobre la construcción y transformación de la capital josefina, motivada por los cambios que introduce el café, utiliza las crónicas de viaje no solo como elemento descriptivo o ilustrativo, sino más 
bien como un instrumento para "explorar nuevas formas de analizar esta fuente, no en forma aislada sino cualitativa y cuantitativamente, como un corpus primario; a partir de la ciudad, con un acercamiento crítico de la fuente y como parte de una literatura imperialista de viajes" (p. 14). Quesada plantea que el estudio de crónicas de viaje permite "analizar las retóricas e intereses presentes en los relatos e intentar decodificar esas miradas imperiales... que los extranjeros hicieron de San José y el Valle Central... [pues] aunque parcial y subjetiva, [es] rica en información sobre la vida cotidiana y urbana" (2011, p. 14).

Ronald Soto-Quirós (2013b), por su parte, utiliza los relatos de viaje con el fin de "evaluar cómo se construyó la "blancura" [costarricense] en los relatos de viajeros anglosajones entre los años 1844 y $1868 \ldots$ En otras palabras, intentamos visualizar la construcción de una "blancura" desde afuera" (párr. 10). Plantea que las construcciones sobre el singular color y temperamento socio-político costarricenses emergieron desde inicios del periodo independiente y destaca el papel central de los textos extranjeros. Según este autor, estas nociones fueron transmitidas por los discursos de extranjeros y consolidadas por las élites nacionales. Enfatiza en los relatos de viajeros como puente que permite observar el establecimiento desde afuera de la idea de un pueblo periférico blanco y con algunas de las cualidades atribuidas a los pueblos considerados superiores (Soto-Quirós, 2013b, párr. 11).

En relación al uso de literatura, específicamente al cuento se puede hacer referencia, entre otros estudios, al trabajo de Florencia Quesada (1998) sobre Barrio Amón, donde utiliza textos como "Un día en el mercado" de Magón, "Mi calle" y "Fantasías de Juan Silvestre" de Carmen Lyra; "Por el amor de Dios" de Luis Dobles Segreda, así como "Crónicas de Húsar Blanco" de Joaquín Vargas. También utiliza las novelas El árbol enfermo de Carlos Gagini y En una silla de ruedas de Carmen Lyra. Quesada recurre a los cuentos y las novelas mencionados como referentes que le permiten reconstruir aspectos como la distribución del barrio, las características de las casas y espacios de sociabilidad, los personajes de élite y aquellos marginales, la cotidianidad, entre otros. ${ }^{4}$

A partir de estos dos ejemplos, se pueden identificar dos tendencias en el uso de literatura como fuente primaria. La primera es su utilización como insumo descriptivo de una situación espacial-temporal particular, como el caso de Sanou, Quesada y Vives (2000) o de Quesada (1998; 2011), pues:

Son escasas las fuentes para reconstruir el entorno urbano y la vida en la ciudad, cuando apenas comenzaba un proceso de conformación de los incipientes estados nacionales y la administración local. La literatura de viajes en el siglo XIX, mayoritariamente de europeos, es una de las fuentes para caracterizar a las ciudades centroamericanas durante el período posterior a la independencia. (Quesada, 2011, p. 14).

La segunda tendencia hace uso de las crónicas como un texto que debe ser interpretado a partir de los elementos contextuales y que tiene una implicación en la 
cotidianidad de las personas a las que se refiere; es decir, la crónica como discurso constructor de relaciones y sujetos sociales. Se puede decir que estas tendencias son niveles diferenciados de interpretación; no obstante, se debe señalar que la segunda tendencia, ejemplificada por Soto-Quirós (2013a; 2013b) y Quesada (2011), es la que más se aproxima a nuestra perspectiva.

Enestesentido,es necesarioreconocer la diferenciaentre crónicade viajey cuento como fuentes para la historia. La crónica hace referencia a un relato, ubicado espacial y temporalmente; se trata pues de un registro, desde una visión particular, de un recorrido a una situación extraña para quien la narra. Mientras, el cuento es, en estricto sentido, una creación ficcional sobre un evento particular. Se podría decir que la crónica puede tener mayor legitimación con respecto al cuento como fuente primaria. No obstante, como se verá a continuación, ambas producciones son susceptibles de análisis como fuentes primarias en tanto su construcción implica la visión particular de un sujeto histórico, que se ha construido como tal a partir de dinámicas socioculturales particulares.

Ahora bien, retomando el análisis propuesto por Amoretti, en relación con el sentido ético-histórico de los textos, es necesario referirnos al momento histórico en que ambos fueron producidos. Como ya se mencionó, la segunda mitad del siglo XIX es el escenario donde se producen los textos; momento caracterizado por grandes cambios en las estructuras sociales, políticas, económicas y subjetivas en Costa Rica. El proceso de independencia, marcado por pulsos y contradicciones, plantea retos sobre los mecanismos adecuados para construir y consolidar un Estado centralizado, sobre el tránsito de la economía colonial al capitalismo agrario, vinculado con el cultivo del café (Molina, 2007).

La llegada de las ideas liberales, y el inicio de su consolidación hacia 1870, con Tomás Guardia en el poder, como consecuencia de un golpe de Estado, contribuye a la profundización de las dinámicas sociales, económicas y políticas en el país. Por medio de la Constitución de 1871, los planteamientos liberales toman cuerpo jurídicamente; esas reformas facilitan la inmersión del pensamiento liberal en las diferentes esferas de la vida política, social, económica y cotidiana de la población que habitaba el país (Díaz, 2005). Las medidas liberales que buscaban alcanzar los ideales de modernidad, progreso y orden, se dirigieron a propiciar una mayor intervención del Estado en elementos como la colonización agrícola, la cobertura de los servicios de salud y educación, la institucionalización e instrumentalización de la ciencia y el desarrollo de infraestructura que facilitaría el mercado interno y, sobre todo, potenciaría el comercio exterior (Goebel, 2003).

Partiendo de esta reflexión, se hace necesario analizar cada una de las fuentes, sus características y, en especial, el sentido ético-histórico que encierran. "San José", forma parte del texto llamado Vacaciones en Costa Rica, de Thomas Francis Meagher. Este texto está escrito en forma de memoria o crónica. ${ }^{5}$ El capítulo en cuestión, titulado "San José", expone con sumo detalle el recorrido que hace el autor por esa ciudad. Se trata de una descripción en la que no solo el viajero 
informa al lector, sino que con cautela deja expuesta su opinión al respecto de lo que observa.

Haciendo alusión a la etimología de la palabra crónica: cronos es el tiempo y, por lo tanto, lo más importante es el relato de los hechos dentro de un orden cronológico. En este caso, Vacaciones en Costa Rica responde al uso del tiempo ordenado, teniendo como guía la estancia del narrador en el país. Relata los acontecimientos dentro de una sucesión.

La crónica es un género narrativo e interpretativo, que cuenta una realidad o suceso a través de la mirada de quien está escribiendo o relatando. Dentro de las características que se pueden destacar de la crónica está la identificación de un inicio con fuerza, precisamente para vincular al lector desde el momento en que se dispone a leer. No es necesario recurrir a la invención: la información que se tiene al alcance es tan verosímil y "real" que solo se debe contar, a partir de la mirada que contempla el espacio.

En las crónicas, el uso de la primera persona es importante para darle credibilidad al contenido. Meagher relata su estancia en San José en primera persona y desde el inicio del recorrido por la ciudad josefina, traslada al lector a ese espacio como si lo estuviera filmando y narrando al mismo tiempo, efecto que se logra empleando la crónica como modelo narratológico:

\footnotetext{
Nos encontramos con un discurso elaborado a partir de la interacción entre el espacio de experiencia y el horizonte de expectativas del viajero. En él la información que se desea transmitir al receptor se dispone a partir de recursos narrativos y descriptivos que tienen como finalidad la reconstrucción discursiva del espacio visitado. (López, 2006, p. 39).
}

Es decir, la crónica como texto literario-periodístico no apuesta por estructurar una historia de forma objetiva; la crónica tiene la particularidad de incorporar el juicio de valor del cronista: se realiza una interpretación de los hechos e introduce el aspecto personal mediante comentarios, figuras literarias, ampliaciones o inclusive alterando el orden mismo en que se presenta el relato. Ahora, toda descripción siempre lleva consigo una carga de subjetividad; por lo tanto, se está conociendo una historia a través del juicio de un solo observador.

La crónica supone un público distante al espacio descrito, es decir, supone un interés del lector por conocer la "realidad" de un mundo que le sería ajeno si no fuese por el relato (López, 2006). En este sentido, es necesario preguntarse cuál es la intención del autor al escribir sobre el país y cuál es el público meta. Un aspecto central de la crónica es la visión del Otro que devela, como lo señala Quesada (2011, p. 18): "cada [relator] en relación con sus objetivos, temáticas, intereses, estilo literario, educación, clase social, nacionalidad, edad y género; y de acuerdo con sus habilidades literarias y tiempo de estadía en la ciudad, produjeron relatos con características que los diferenciaron". 
Antes de aproximarse a esta respuesta, es necesario brindar alguna información sobre el autor. Meagher nació en Irlanda en el año 1823; fue líder del movimiento Irlanda Joven, de tendencia nacionalista. En 1848 fue desterrado y un año después se fugó y migró hacia Estados Unidos. En la introducción a su libro, se menciona que fue seguidor de William Walker y que incluso celebró la retirada del ejército costarricense en Rivas: "Las aclaraciones lanzadas hoy en el parque anuncian que la bandera de Costa Rica está hecha pedazos" (Meagher, 1923, p. x). Su viaje a Costa Rica se dio entre abril o mayo de 1858 y se menciona que su objetivo era vacacionar, pero también era un viaje de estudios. De hecho, en el texto menciona que: "sería un testimonio de su aprecio y vehemente deseo de ayudarnos en nuestra laudables investigaciones" (Meagher, 1902, p. 382).

No obstante, en su texto no queda claro cuál es el centro de sus investigaciones. Raúl Aguilar (2005) menciona tres razones que explican la visita de numerosos viajeros, cuyos relatos son traducidos y editados por Ricardo Fernández Guardia, en el título Costa Rica en el siglo XIX. Antología de viajeros, de 1902. Estas tres razones son: interés científico, promoción de empresas de colonización y actividades comerciales en Europa e impulsar la construcción de un canal interoceánico. A partir de este planteamiento, se puede mirar desde otro lugar, la narrativa de Thomas quien señala, de manera constante, las carencias en términos materiales, de infraestructura, de objetos de lujo, entre otros, así como la presencia de extranjeros, cuya estancia en el país mejora esas carencias:

\footnotetext{
Tratándose de las iglesias hispanoamericanas, es sorprendente su falta de ornamentos y tesoros. Su desnudez externa, para decir lo menos posible, es un indicio honesto de la miseria interna. Sin embargo, la de San Juan de Dios, cuyo arquitecto es el señor Francisco Kurtze, un hábil alemán, será una excepción grandiosa. (Meagher, 1902, p. 382).
}

Además, en la crónica de Meagher, se hace referencia a los filibusteros y a las luchas en su contra, así como a la presencia, muy reconocida por parte de las élites, de personajes vinculados con la empresa interoceánica, como es el caso de Felix Belly. En este sentido, autoras como Obregón (1994), han planteado que Meagher, entre otros, funcionaba como espía de William Walker en el país al brindarle información sobre las acciones del gobierno de Juan Rafael Mora.

El propio Ricardo Fernández Guardia, en el año 1902, hace una referencia al contexto caracterizado por un temor y recelo frente a los estadounidenses en la época:

La pintura que hace del país es muy amena y los juicios que acerca de él emite están impregnados de mucha benevolencia, lo que revela una ecuanimidad grande, porque Meagher no puede haber dejado de notar la prevención que en aquella época reinaba en Costa Rica sobre Estados Unidos, sentimiento muy explicable a raíz de la sangrienta guerra filibustera y avivada por las amenazas de nuevas invasiones de Walker, apoyados por intereses norteamericanos. (Fernández, 1902, p. xiii). 
La traducción y publicación del libro se hace casi 50 años después de su producción, lo cual puede explicar el porqué existe una relectura a la presencia estadounidense en el país. En el caso particular de Meagher, Fernández Guardia asegura que "el estilo es brillante y muy animada con reminiscencias clásicas y destellos de fino humor anglosajón" (Fernández, 1902, p. xii). El interés de Fernández por traducir los textos producidos por extranjeros de las décadas de 1850-1860, se puede vincular con su visión eurocentrista y academicista de la literatura y la historia en la época. Fernández como representante del discurso nacionalista academicista (Quesada, 1986) enfatizaba en la importancia de traducir esos textos para "el desarrollo de la cultura general en nuestro país" (Fernández, 1902, p. vii).

Con respecto al texto "El clis de sol", aparece publicado por primera vez en el periódico La República, en 1896 (Amoretti, 2002). Se puede señalar que es una fuente literaria narrativa, específicamente cuento, ya que en él se describe una situación cotidiana, protagonizada por pocos personajes y narrada de forma breve.

Como género literario, el cuento hace su aparición en Costa Rica tardíamente en el siglo XIX. De acuerdo con Seymour Menton (1964), varios son los factores que explican este fenómeno y también las características de la literatura costarricense. Primero, el crítico alude al aislamiento de Costa Rica, en la época colonial, por falta de minas, ausencia de población para esclavizar y como consecuencia de esto, su condición de pobreza. Segundo, dentro del mismo territorio los pocos habitantes vivían aislados unos de otros. Tercero, como resultado de su pobreza, no hubo contacto con España ni las otras colonias, esto trajo como consecuencia la ausencia de una universidad e imprenta, impidiendo el conocimiento de la literatura del Siglo de Oro español y el movimiento enciclopédico e ilustrado del siglo XVIII: "las pocas familias ricas mandaban a sus hijos a la Universidad de León en Nicaragua o a la de San Carlos en la lejana Guatemala, cabecera de la Capitanía General" (Menton, 1964, p. 6). Cuarto, al vivir su proceso de formación de República, entre 1821 y 1889, su objetivo no era literario, sino más bien de otra índole.

Los textos literarios de finales de siglo XIX respondían a cuadros de costumbres, es decir, quienes escribían se dedicaron a retratar las costumbres de la época, específicamente, de las clases populares. Las características de estos textos, incluido "El clis de sol", fueron el tono intenso, burlesco e irónico hacia las clases desprestigiadas, la presencia femenina como símbolo de sumisión y privada del espacio público, así como el enaltecimiento de la cultura letrada como dueña de la palabra y la razón.

Álvaro Quesada, entre otros autores, describe el trabajo de Manuel González dentro de este movimiento costumbrista costarricense, el cual retoma elementos del movimiento clásico y realiza variantes: "Magón no sólo incluye en la literatura temas y asuntos de la vida popular, sino que otorga dignidad artístico-literaria al lenguaje "concho" y al género costumbrista, relegados hasta entonces al limbo literario del periodismo humorístico o la expresión folklórica" (Quesada, 1986, p. 111). Esta forma de incorporar las costumbres, pero sobre todo los códigos 
lingüísticos populares, generó debate a nivel nacional, pues algunos sostenían que esta incorporación vulgarizaba el arte literario (Quesada, 1986).

En este sentido, es interesante analizar la ruptura simbólica que pudo generar la inserción de personajes, situaciones y prácticas populares en la producción literaria. Es decir, esta incorporación podría ser entendida como una forma de irrumpir en los cánones literarios, pero sobre todo sociales. No obstante, no se puede idealizar esta incorporación. Y para comprenderla en términos sociopolíticos, es necesario hacer referencia al autor del cuento. Magón es reconocido como uno de los representantes más importantes del movimiento costumbrista en el país. Este autor nació en 1864 y murió en 1936; fue periodista y político liberal reconocido, que migró hacia Estados Unidos, donde desempeñó cargos diplomáticos. Se le reconoce como uno de creadores de las imágenes nacionales (Sistema Nacional de Bibliotecas, s.f.). Magón formó parte del grupo conocido como el Olimpo, un grupo de élite de intelectuales y políticos pertenecientes a la oligarquía cafetalera (Quesada, 1986):

\begin{abstract}
Mientras los políticos se encargan de montar el nuevo Estado liberal, con sus leyes, códigos e instituciones, los otros intelectuales se encargan de la elaborar la nueva mitología oficial costarricense, con sus héroes, gestas y monumentos; con su historia, cultura y su literatura nacionales... El periodo de juventud y formación de estos escritores coincide con la etapa de consolidación del Estado, bajo la égida de la oligarquía liberal en la década de 1880. Así, el papel histórico, literario e ideológico que cumplieron estos autores, consistió en elaborar un modelo de literatura nacional que respondiera al proyecto nacionalista y civilizador que se iniciaba bajo el signo del liberalismo oligárquico. (Quesada, 1998, pp. 35-36).
\end{abstract}

Este grupo se encargó de construir una serie de imágenes sobre la nacionalidad, que permitían construir formas identitarias homogéneas que garantizaran la inserción de las mayorías en el nuevo sistema político-económico. En este contexto, se puede entender la aseveración de Amoretti (2000), con respecto a las pretensiones de los escritores de la época de escribir la historia y particularmente del autor costumbrista de asumirse como historiador de su tiempo.

La concentración de la literatura en el Valle Central, excluyendo las culturas indígena, afrocaribeña, ganadera y minera, son una forma de reforzar la supuesta homogeneidad. De acuerdo con Quesada (2008), "esta exclusión facilitaba la identificación oligárquica con la cultura europea y fortalecía la imagen de un país, de una nación occidental civilizada" (p. 15).

Según Amoretti (2000, p. 1), el movimiento costumbrista costarricense presenta una serie de características particulares. En el caso de "El clis de sol", se evidencia la presencia de algunos conceptos relativos a las costumbres, la comunidad y la identidad nacionales; además de criterios de aceptabilidad como la objetividad y veracidad que se muestran en frases como "No es cuento, es una historia que sale de mi pluma como ha ido brotando de los labios de ñor Cornelio" o "Podría tal vez entrar en un análisis serio del asunto, pero me reservo para cuando haya oído las opiniones de mis lectores". Asimismo, el cuento presenta la ironía como 
modalidad discursiva para formular una crítica burlesca, la cual es el eje central del texto y aparece claramente en frases como "No lo sabía, y me sorprende que usted lo hubiera adivinado sin tener ninguna instrucción". En el ejemplo anterior, además subyace una jerarquización de los saberes, donde implícitamente se emite una burla del saber popular.

\section{VOCES, ESPACIOS Y CULTURAS POPULARES}

A pesar de las diferencias que existen en los textos (de perspectiva e interés particular del autor, de género literario, entre otras), las voces que aparecen presentan algunas similitudes. Las voces así como las intensidades con que estas aparecen se vinculan con el autor, el tipo de narrador y el lector que es interpelado. Es decir, las voces existen gracias al juego entre autor, narrador y lector.

En ambos textos se puede apreciar la existencia de dos tipos de voz: la hegemónica y la subalterna. Es decir, el centro y la periferia aparecen en un mismo texto; lo hegemónico intentará imponerse y lo popular evidenciará su variedad, su dinamismo y la línea tensional mostrará los aspectos más débiles de su principal oponente.

\section{EL CENTRO: VOCES HEGEMÓNICAS Y EXCLUSIÓN}

Los escritores que desde espacios privilegiados procuran ratificar su posición y dominio mediante un discurso legitimador y consecuente con el imaginario social impuesto, apuestan por consolidar cada una de las prácticas sociales y culturales a favor de un proyecto ideológico que suponga ser integrador y variado, involucrando a todos sus miembros "sin importar" su condición. La necesidad de constituir al país como nación, de consolidar un proyecto y empoderar su estabilidad económica, llevó a la clase privilegiada o bien cultura hegemónica a emplear varias estrategias que permitieran resaltar sus criterios y asimilar sus patrones culturales, en aras de someter a los más débiles.

Dos son las señales más evidentes en "San José" y "El clis de sol" que se pueden asociar a estos mecanismos de consolidación de clase: lo scópico y el discurso. Con respecto a lo scópico, se puede señalar que se presenta como la posibilidad de describir el contexto y a sus actores de acuerdo con ciertos paradigmas. Un ojo, una mirada que recorre toda la ciudad y encasilla todo cuanto observa.

El texto titulado "San José" es descrito por una mirada hegemónica, en este caso la de Meagher y, cual especie de documental, se le presenta al lector. Son los ojos del narrador, las representaciones del narrador y los criterios de ese narrador los que miran y juzgan, desde arriba. La mirada hegemónica que observa en "El clis de sol" se caracteriza por ser penetrante y burlesca. Magón se inserta como husmeador 
en el cuento. Mira con detenimiento a su oponente Cornelio y le dice al lector cómo debe leerse la historia y bajo qué parámetros hacerlo:

\begin{abstract}
Y tanto me sorprendió la maravilla el no comunicarla para que los sabios y los observadores estudien el caso con el detenimiento que se merece. Podría tal vez entrar en un análisis serio del asunto, pero me reservo para cuando haya oído las opiniones de mis lectores. Va pues, monda y lironda, la consabida maravilla. (González, 2012,p. 79).
\end{abstract}

En cuanto a la señal del discurso, conlleva no solo los términos empleados por los intelectuales de la época, sino los tonos, los silencios y la carga semántica que se teje a la luz de cada una de las frases empleadas por ellos. El discurso es el mecanismo de control empleado por las élites, porque a partir de él se logra construir el proyecto hegemónico para mantenerse en el poder.

En cada uno de los textos en estudio, se visualizan términos, frases y construcciones gramaticales con una carga semántica capaz de persuadir y dejar por sentada una ideología. El discurso de las clases hegemónicas se caracteriza por ser imperativo, prejuicioso y reiterativo. Desde el lenguaje se construyen los aparatos hegemónicos: el Estado, la Iglesia, la Escuela y la Familia, instituciones garantes de la reproducción de imaginarios sociales.

La señal discursiva en "San José" queda evidenciada desde el uso de adjetivos cargados de prejuicios, los símiles con Europa y Estados Unidos y el tejido narrativo en su conjunto, que marca no solo la distancia geográfica del narrador y el texto, sino la posición jerárquica, connotando un: usted ahí - allá; y yo, aquí o acá, pero nunca unidos. Queda clara la intención de esa voz extranjera de no generar vínculo con las prácticas culturales:

\footnotetext{
Este juego (peleas de gallos) cruel, absurdo y villano está pasando rápidamente de moda. Hubo un tiempo, y de esto hace apenas cinco o seis años, en que el presidente y todo el gabinete se dejaban ver en la gallera; pero ahora rara vez y quizás nunca se encuentra en ella a un político distinguido y mucho menos a un estadista, aun en vísperas de una elección. (Meagher, 1902, p. 380).
}

En "San Josée, las prácticas culturales son señaladas como nocivas, perversas e inmorales. Recuérdese las peleas de gallos, las actividades teatrales y por qué no, la vagabundería en sí y las costumbres indígenas. En "El clis de sol", los campesinos se definen, desde la hegemonía, como feos, ignorantes y grotescos. Su discurso es impopular, incorrecto e incluso mal estructurado. Cornelio responde a este tipo de esquemas.

Como se ha señalado, estas voces hegemónicas se caracterizan por provenir de las instancias o grupos con una cuota de poder económico y político significativa; representan a las instancias que intentan moldear a una Costa Rica con conflictos políticos y que recién se insertaba al modelo económico mundial por medio del cultivo de café. La privatización de la tierra y la mercantilización de la mano de obra como parte 
del proceso de expansión cafetalera, intensificó entre grupos sociales diferencias que se expresaban en términos étnicos y de consumo (Molina, 2007, pp. 8, 18):

La vertiginosa expansión del aparato judicial no era casual: una temprana tensión cultural pronto comenzó a perfilarse entre los sectores acomodados urbanos y rurales (en particular la burguesía cafetalera), que tendían a la europeización y secularización de sus visiones de mundo, y el grueso de campesinos y artesanos. Las identidades populares, de base colonial y religiosa, estaban lejos de integrar los nuevos valores asociados con el ascenso del capitalismo agrario: entre otros, una disciplina laboral más estricta, el énfasis en lo privado y lo individual a costa de lo comunal y la mercantilización de diversas dimensiones de la vida cotidiana... Las quejas de los patronos por la indisciplina y los robos de sus trabajadores no tardaron en evidenciarse en la prensa de la época, por lo que el Estado rápidamente respondió con un esfuerzo sistemático por "moralizar" a los sectores populares, el cual fue apoyado por los eclesiásticos y por las familias más pudientes de los barrios de trabajadores en las ciudades y de las comunidades campesinas en el agro. (Molina, 2007, p. 22).

El poder político oligárquico cafetalero se fortalecía por vías jurídicas tendientes a centralizar en pocas manos el floreciente Estado, como se representa en el texto "San José":

Para ejercer el derecho al sufragio, el ciudadano tiene que ser mayor de veinticinco años, padre o cabeza de familia y poseer bienes raíces por valor de $\$ 1.000 \ldots$ Para ser diputado al Congreso se requiere ser mayor de veinticinco años, poseer bienes raíces por valor de $\$ 3.000$ o tener profesión liberal... El presidente y el vicepresidente son electos por un periodo de seis años por asambleas electorales... Para el ejercicio de ambas funciones se necesita ser mayor de treinta años, tener bienes por valor de $\$ 10.000$ y ser casado o viudo. (Meagher, 1902, pp. 406-407).

Los narradores forman parte de estas voces hegemónicas; en el caso de "San José", el autor-narrador claramente es una voz hegemónica encarnada en un extranjero, que accede en un periodo relativamente corto a las élites políticas, de la iglesia y del círculo de extranjeros adinerados de San José. La presencia de extranjeros, sobre todo de Inglaterra, Estados Unidos, Alemania, Italia, entre otros, se fortaleció a partir de la segunda mitad del siglo XIX, debido al aumento de inversión de capital en la producción cafetalera, la colonización agrícola y el desarrollo de los ferrocarriles en el país (Molina, 2007, p. 25).

Además, se puede mencionar que al tratarse de una traducción, Fernández Guardia podría ser también un autor, pues es gracias a él que se tiene acceso a los textos en español y como se mencionó anteriormente, esta acción no es ingenua, sino que corresponde a la intención del traductor de ofrecer textos a "la juventud estudiosa" para que esta se deleite con su lectura y conozca bien el pasado del país (Meagher, 1923, p. vii). Fernández Guardia, en este caso, representa a la voz hegemónica intelectual, igual a la que aparece en "El clis de sol", con las referencias constantes a la sabiduría de Magón: 
¿Pos no había de rirme, don Magón, cuando veo que un probe inorante como yo, un campiruso pion, sabe más que un hombre como usté que todos dicen qu'es tan sabido, tan leído y que hasta leyes onde el Presidente con los menistros? (González, 2012, p. 80).

Como lo señala Amoretti (2000), en el relato costumbrista la autoridad ficcional tiene como condición indispensable el seguimiento a un protocolo, la presencia de un verosímil pragmático, instaurado gracias a la construcción de un "contexto perceptual haciendo coincidir la presencia del locutor y del interlocutor y fingir entre ellos la existencia de un consabido y de un acuerdo preinstalado" (p. 30). En este sentido, se puede señalar que la interpelación inicial de Magón a los lectores como sabios y capaces de comprender la ironía que conlleva la adjetivación de la situación como "maravillosa", crea una complicidad que les coloca en el mismo lugar.

La complicidad se establece en el mismo acto de lectura, lo cual remite al contexto en que surge el texto, el cual se caracteriza por una incipiente educación pública. El incremento significativo en el presupuesto del Estado para la educación se da a partir del último quinquenio del siglo XIX, periodo que coincide con las medidas de la reforma educativa, que tenía como propósito la divulgación de las ideas liberales entre las clases populares (Díaz, 2005, p. 47). Es decir, el lector esperado en ese contexto compartía no solo un mundo simbólico, sino económico y social con el autor-narrador, que permitía su asistencia a la educación formal y por tanto, su posibilidad de leer.

En este sentido, se pueden anotar algunas diferencias entre los textos con respecto a las voces hegemónicas. Por ejemplo, en "El clis de sol" aparece con mayor claridad la voz educativa como un ente legitimador: "La mestra me las quiere y les cuece la ropa". Lo anterior, se vincula con el paulatino crecimiento de la educación pública como espacio de "civilización", pues tal como lo señala Quesada (1998):

En este proyecto juega un papel predominante la educación estatal, que se consolida con las reformas educativas de $1886 \ldots$.. La escuela centro de promoción de nuevas aptitudes y destrezas, es también paradójicamente, el instrumento adecuado para reproducir la distribución desigual de esas aptitudes y destrezas: educación elemental y religiosa que fomente la obediencia y el respeto a la tradición y la autoridad, como forma de preservar los valores "cívicos" o "morales", para la gran mayoría del pueblo y las mujeres. (p. 26).

Mientras, en "San José", el componente militar y policial aparece de manera constante, aunque es descrito como decadente, insignificante: "Allí se ven los jinetes elegantes de la capital, es el punto de reunión de los carruajes y una o dos veces en el año se sirve para establecer campamentos militares". El lugar central del poder militar se vincula con el proceso de modernización que se le da en la administración Mora Porras, que entre otras medidas aumenta el número de soldados, busca su educación e invierte en la compra de armas (Díaz, 2005, pp. 37-38). 
Es justamente esta modernización la que posibilita la Campaña Nacional 1856-1857. Las referencias en "San José" de este evento son múltiples; la muerte y la locura aparecen vinculadas con lo militar:

Los pacientes eran soldados costarricenses que habían peleado a las órdenes del general Cañas en San Jorge, en el lago de Nicaragua. En frente de ellos yacían tres soldados de Walker, que padecían de úlceras agudas a consecuencia de la mala vida que habían llevado a la intemperie y por falta de cuidados. (Meagher, 1902, p. 408).

\section{LA PERIFERIA: VOCES SUBALTERNAS Y ESPACIOS EN TENSIÓN}

Las voces subalternas aparecen de forma tímida en los textos, pero estas voces subalternas tras su juego enmarañado de palabras resultan ser la piedra en el zapato de aquellas que creen tenerlo todo bajo control. Si de algo se debe estar seguro es de que la lectura de la literatura no debe ser complaciente, sino cuestionante de las representaciones sociales que allí se muestran. Entre estas voces podemos ubicar a las mujeres, los campesinos, las poblaciones indígenas, "los enfermos" y "las locas".

Roger Chartier (1994) en su estudio sobre la cultura popular, recuerda dos modelos de análisis: uno, donde se le concibe como autónoma de la cultura hegemónica, es decir, con su propio sistema de símbolos y otro, en el que tradicionalmente se le ha definido: supeditada a los grupos de poder. Si bien no se pretende dar una definición de cultura popular, sí, por lo menos, ubicarla en un espacio tensional que señala, cuestiona y enfrenta lo establecido por la hegemonía y la oficialidad.

Álvaro Quesada (1998,p. 28) afirma también esa tensión existente entre ambas culturas que con la idea de la construcción del proyecto nacional oligárquico quedan evidenciadas. Por un lado, la tendencia a la unidad y a la asimilación del paradigma hegemónico y, por otro lado, los choques y resistencias de grupos subalternos contra el modelo de realidad nacional que tendía a reprimir, mutilar y excluir su existencia.

Ahora bien, cabe preguntarse si realmente las voces subalternas aparecen en estos textos, ¿son sus voces o son más bien los discursos de las voces hegemónicas sobre ellas? En "San José", la mirada que escudriña el entorno es muy particular: es una mirada extranjera con intereses políticos específicos, que no comparte tan siquiera el código lingüístico mínimo (español) y cuya narración da cuenta de dificultades para descifrar el mundo simbólico al cual se acerca. Su mirada extranjera permea su descripción, que si bien es detallada no logra comprender o descifrar el mundo simbólico, de significados y prácticas que se presenta ante sus ojos. No existe posibilidad de comprender a San José ni a sus habitantes, si no es por medio de sus parámetros culturales e ideológicos: "El Campo de Marte es para San José lo que el Bois de Boulogne para París". Meagher tiene dificultades para penetrar en 
el mundo de significantes y significados de prácticas y personajes que reconstruye como salvajes, pintorescos y aburridos:

Los policías son pintorescos. Un poco después de la puesta del sol les pasan revista en la plaza y los mandan a sus puestos. Con una carabina colgada del hombro, una espada corta con empuñadura de bronce, una cartuchera, un sombrero de paja roñoso y una manta vieja a guisa de uniforme, patrullan la ciudad silenciosa hasta el amanecer, y, al terminar su pesada vigilia rezan la oración del sereno "Ave María Purísima", en el tono más lúgubre. (Meagher, 1902, p. 376).

Al denominar a los policías como pintorescos por su forma de vestir y su vínculo con la religión, da cuenta de una lejanía que no puede comprender la relación estrecha entre Iglesia y Estado, que tiene lugar desde la colonia. Asimismo, en su descripción de la quema de Judas, el paisaje se describe como decadente, salvaje y grotesco, no solo por las acciones que tienen lugar (la quema del muñeco), sino también por las dinámicas que provocan una mezcla de grupos sociales que no puede ser comprendida:

Todo en menos de dos minutos y en medio del redoble de los tambores, de los alaridos agudísimos en los muchachos, el canto de los gallos, de los ladridos de los perros, de las risitas entre dientes de las modestas señoritas y señoras, de la cháchara de los loros, de una granizada de piedras y de la gritería, maldiciones, y regocijo estrepitoso de militares y paisanos, clérigos, indigentes y patricios. (Meagher, 1902, p. 380).

En el caso de "San José", las voces subalternas aparecen no necesariamente con voz propia, pero en el sentido que plantea Amoretti, el texto sí permite reconocer el mundo ético y simbólico en que surge el relato. Por esta razón, en él se evidencian prácticas sociales permeadas por el poder, representado en códigos físicos, sociales y culturales. Por ejemplo, la mención de Meagher al señor Calvo, ministro de Gobernación, remite a cuestionar el lugar de las poblaciones indígenas en la construcción del Estado-nación: "El señor Calvo es... un indio impasible del pueblo de Quircot y como ministro de Gobernación resulta singularmente útil. Sin remordimientos le achacan todos los errores del Gobierno. Resignado y capaz de llevar la carga hasta el final de su vida, ningún presidente ha pensado en removerlo" (Meagher, 1902, p. 398). Si bien no está presente de forma explícita el discurso de Calvo sobre su situación, sí se puede afirmar que esta descripción muestra un mundo donde lo indígena era rechazado y sustituido por lo mestizo; lo indígena era valorado de forma utilitaria.

Otras voces que emergen a partir de la narración, pero sobre todo de los silencios, son las voces de las mujeres. El lugar que les asigna Meagher en su relato las presenta como "locas por la religión", "modestas", "las encargadas de las esposas de los personajes importantes en las actividades sociales de élite". Las mujeres no aparecen con voz propia, debido a los silencios del autor con respecto a ellas. Esta situación debe entenderse en el contexto nacional, específicamente en lo referido al lugar de la mujer que tanto en las élites como en los sectores populares era colocada en 
una posición de subordinación. La inclusión de la mujer en el trabajo cafetalero y en la educación buscaba fortalecer la familia patriarcal (como unidad básica de la sociedad) y socializar los valores liberales en la educación liberal de los hijos (Silva, 1989).

El tema de género, estudiado a la luz del contexto del siglo XIX, ofrece muy pocas lecturas variadas. Los estudiosos coinciden en que la mujer era símbolo de sumisión y el espacio donde se podía desarrollar era el privado o doméstico. Sus labores estaban condicionadas a las necesidades masculinas. Fue una época difícil, forzosa y penosa. La mujer fue desplazada, silenciada y condenada a no tener su propia identidad, sino que esta dependía del otro, en este caso su padre o su esposo. Aquellas que optaban por tomar sus propias decisiones y escoger su estilo de vida eran consideradas seres demoníacos, y las que constantemente denunciaban y exigían sus derechos, seres desquiciados.

Un ejemplo de la literatura de la época es el personaje Magdalena, de Ricardo Fernández Guardia, obra que a inicios del siglo XX fue muy significativa, pues evidenció la lucha de una mujer por su libertad, para que la sociedad no impusiera en ella sus paradigmas. Y los personajes femeninos del mismo Magón, mujeres que rompen el código marital y deciden vivir una pasión o relación amorosa fuera de la norma imperante.

En el caso de "San José", se menciona en un apartado la visita del narrador al hospital, un lugar lúgubre y aislado cuyas condiciones eran inhumanas para quienes se encontraban allí. Lo curioso de este caso, fue encontrarse la figura femenina hospitalizada por demencia. Si esto se analiza a través de la historia, se tiene que la locura femenina, cual enfermedad "amenazante", ha sido una razón para recluir a la mujer en lo más recóndito de la casa, o bien, para conducirla "hacia un territorio invisible, en otra parte del mundo" (Macaya, 1997, p. 75), en el caso de "San José", un hospital psiquiátrico:

En el departamento de orates del hospital había dos mujeres... las dos mujeres estaban locas por motivos de religión. Una de ellas había cubierto las paredes del cuarto en que estaban encerradas con los más extraños jeroglíficos, calaveras... La otra mujer, arrodajada sobre una mesa, ofrecía el cuadro de la más espantosa desolación. (Meagher, 1902, p. 411).

La cita anterior supone el estado demencial femenino. Los demás reclusos, no están locos, solo enfermos físicamente, cuerdos para contar su propia historia y ser escuchados, como lo que sucedió con el tercer paciente que vio el narrador, cuya historia es totalmente referencial a su vida. En fin, la voz masculina tiene la palabra, mientras que la voz femenina es silenciada y aislada. El único camino es generar su discurso a través de jeroglíficos en las paredes del cuarto, un espacio cerrado y ajeno a todo contexto. Y esto no es más que el discurso femenino visto desde la óptica masculina: el discurso de la mujer demonio.

El proceso de construcción de identidad, Emilia Macaya (1997) lo explica dentro de la cultura patriarcal, mediante la dicotomía mujer ángel y mujer demonio: 
La mujer angélica es un ser sin historia propia, puesto que debe constituirse, más bien, en espejo del orden masculino al que se subordina... La pasividad se vuelve además su rasgo característico, puesto que en ella la acción aparece reducida a generar hijos que perpetúen el nombre del padre... El ángel del mundo, amada inmóvil e incontaminada, obtiene su pleno sentido como divinidad en los cielos... No sólo el pasado del siglo XIX y sus productos literarios está poblado de seres de inusitada esbeltez que desafía la natural conformación del cuerpo humano. (pp. 71-72).

En el caso de la mujer demonio, esta es constituida así, en el momento en que el patriarcalismo no puede modelar su ser; entonces, la convierte en un ser monstruoso. Si este monstruo persiste en actuar, el orden de los patriarcas tratará de decapitarlo. Las mujeres recluidas en ese hospital se encuentran desquiciadas por practicar una religión. Será este discurso su mecanismo de defensa más inmediato para salirse de la norma y el castigo ante tal evasión a la ley, es el internamiento por locura. El narrador es muy claro, las dos mujeres están recluidas en ese hospital por motivos religiosos.

A todo esto, los estudios de Rose Murano y Leonardo Boff (2004) ${ }^{6}$ afirman que en la lucha por hacer valer sus intereses y derechos, la mujer ha tenido fuertes enfrentamientos con la cultura oficial. La propuesta de estos investigadores está orientada al gozo y a la figura del andrógino, un gozo en el que participen ambos géneros y se produzcan mujeres masculinizadas y hombres feminizados; en otras palabras, mujeres compartiendo las labores que por tanto tiempo han sido exclusivas del hombre y hombres actuando en el espacio privado que también ha sido el refugio durante siglos de la mujer. La androginia, entonces, será la reunificación de los sexos, dentro de cada uno: hombre y mujer, capaz de consentir esa búsqueda uno al otro, no desde la diferencia, sino desde la complementación.

En suma, se trata de apostar por hombres y mujeres capaces de reordenar los aparatos ideológicos masculinos que "tienen como principio organizador el poder" (Murano y Boff, 2004, p. 198); que si bien el discurso del siglo XIX nunca lo contempló, quedará como una posible idea sugerida como solución a la división tan marcada que durante ese siglo se hizo de los roles de género.

Por otra parte, uno de los espacios repulsivos para el narrador de "San José" es la gallera; la descripción detallada al respecto de este lugar permite saber que se trata de un espacio polifónico y con diversidad cultural. A las galleras no solo asiste la plebe, sino que dicha actividad convierte este espacio en convergencia de todas las clases sociales:

Era un domingo de Pentecostés y el lugar estaba atestado de gente. Todas las clases sociales estaban allí representadas: el mercader y el buhonero, coroneles con charreteras relumbrantes y soldados rasos, doctores, abogados, empleados de Gobierno, padres de familia, elegantes caballeros con holgados chalecos y cabezas grises, jóvenes de diez y ocho años y aún menos. (Meagher, 1902, pp. 378-379). 
Este espacio es propicio para desahogarse, denunciar. Es un espacio de liberación en el que se encuentran elementos muy propios de la cultura popular: la euforia, la risa, las inversiones, la variedad y la igualdad.

Al no permitir el texto darles voz a estos grupos sociales presentes en las galleras, se intuye que más que un espacio de confrontación es un espacio de liberación. Y una vez más, la práctica popular es el elemento unificador. Sin embargo, no se debe perder de vista el hecho de que aquí están presentes esas voces que denunciarán y se resistirán a cualquier decisión tomada en su desventaja.

Meagher no comprende las peleas de gallos más que como una práctica vil, propia del pueblo, que poco a poco se va desligando de las élites políticas, que regularmente asistían. Lo que es leído como un pasar de moda, como una transición a la civilización por propia voluntad, en realidad se puede vincular con los cambios a nivel jurídico y social que buscaban un mayor control social por parte del Estado, de la vida social de las personas y sobre todo, de aquellas prácticas de entretenimiento. El sostenimiento de la producción cafetalera estaba mediatizado por la posibilidad de contar con trabajadores responsables, obedientes, razón por la cual el Estado liberal debía regular el trabajo, el tiempo libre. Como lo señala Enríquez (2001):

\begin{abstract}
$\mathrm{Al}$ afianzarse más el Estado y al ampliarse las diversiones, surgen reformas a dicho reglamento. También aparecen decretos y otros reglamentos que en forma específica se refieren a juegos, espectáculos públicos, licores, días feriados, cinematógrafos, peleas de gallos, etc. En todos aparecen las instituciones o personas que se encargan de velar por su cumplimiento, se contempla el papel que en primer instancia juega el gobernador, luego la municipalidad y el agente de policía o el jefe político de cada lugar. (párr. 2).
\end{abstract}

Estas regulaciones jurídicas se incorporan poco a poco y construyen un mundo de prácticas y significados distintos que a su vez configuran subjetividades que dan sostén al sistema político, económico y social.

El teatro es otro espacio para el pueblo. Sin embargo, en este periodo del siglo XIX fue un lugar amenazante para los grupos hegemónicos, principalmente para la Iglesia. El teatro llegó a simbolizar un espacio de prácticas culturales diabólicas, impuras y herejes. La Iglesia se manifestó siempre en contra de las funciones que se presentaban en él.

El narrador de "San José" presenta el teatro como una opción de entretenimiento, cuyo diseño interior propicia la separación de clases. No obstante, a él acuden todos los grupos sociales. Se convierte entonces en otro espacio polifónico y plurisignificativo:

El teatro está igualmente abierto los domingos por la noche... Tiene dos filas de palcos; debajo de la más baja hay tres hileras de bancos separados de la platea por barras de hierro horizontales, que tienen el aspecto de una jaula semisubterránea destinada a curiosidades salvajes. No pude dar con el objeto de esta disposición, se debe probablemente al temor de que la gente pobre se enfurezca al ponerse en contacto con la civilización de la platea. (Meagher, 1902, pp. 404-405). 
No obstante, este ejemplo define el discurso excluyente del narrador y el estereotipo que tiene de los sectores populares, definiéndolos como bárbaros, revoltosos y salvajes.

El teatro ${ }^{7}$ se presenta en un contexto muy variado: 1- De diversiones públicas y vida cotidiana, jamás como una zona de conflicto entre clases. La lectura del extranjero está mediatizada por los estereotipos. 2- Se presenta también en un contexto cultural con corrientes estéticas y modas temáticas y 3 - en un contexto de poder pues había censura, vigilancia, privilegios y beneficios. Se trata de un lugar propicio para escuchar esas voces populares silenciadas por los sectores dominantes.

Con respecto a "El clis de sol", la voz hegemónica encarnada por Magón, representante de la Generación del Olimpo, entra en diálogo con la voz del campesino, Ñor Cornelio. Según Amoretti (2000), este diálogo se sostiene en la separación de las voces, lo cual es claro en el texto: Magón representa aparentemente la sabiduría, la intelectualidad y al Estado, mientras que Nor Cornelio representa la ignorancia y la ingenuidad. Se emula un diálogo de saberes que tiene la intención de destruir, pero a la vez dar la victoria al oponente a través de "la manipulación liberal del conocimiento y sus resultados opresores. Aquí la única relación intersubjetiva es la que se necesita para validar un status quo" (p. 33).

Es en este sentido que la voz subalterna debe leerse más allá de la representación del campesino como ignorante o idiota; Nor Cornelio aparece como una voz subalterna que engaña tanto al autor-narrador como al lector. El engaño consiste en encubrir el conocimiento de la infidelidad de la esposa y enmascararlo de ignorancia y total respeto a la voz hegemónica del extranjero. En este sentido, Nor Cornelio con su engaño descubre y denuncia a la ideología "al menos, fija sus límites, gesto suficiente para atacarla en su más fundamental debilidad: su incapacidad para reconocer sus límites reales" (Amoretti, 2000, p. 34). El campesino justifica su supuesta ignorancia por medio de la voz del extranjero, voz altamente legitimada en la época:

\footnotetext{
Pa qué engañarlo, don Magón. Yo no juí el que adevinó el busiles ¿Usté conoce a un mestro italiano que hizo la torre de la iglesia de la villa: un hombre gato, pelo colorao, muy blanco y muy macizo que come en casa dende hace cuatro años... Por él jue el que m’emplicó la cosa del clis de sol. (González, 2012, p. 81).
}

Con su engaño muestra los límites del Estado liberal, pues el campesino es mucho más que lo que el discurso hegemónico señala; es capaz de comprender los códigos y usarlos en su beneficio. El poder liberal no es absoluto.

La descripción de Magón de las niñas devela discursos y prácticas sociales que vinculan el fenotipo blanco y rubio con lo bello, divino y placentero; mientras el fenotipo moreno con lo tosco, feo y sucio:

María de los Dolores y María del Pilar, ambas rubias como una espiga, blancas y rosadas como durazno maduro y lindas como si fueran imágenes, según la expresión de ñor Cornelio. Contrastaban la belleza infantil de las gemelas con la sincera incorrección de los rasgos fisionómicos de ñor Cornelio, feo si los 
hay, moreno subido y tosco hasta lo sucio de las uñas y lo rajado de los talones.

(González, 2012, p. 79).

El engaño de Ñor Cornelio es encubrir la infidelidad con la voz del extranjero, con su supuesto saber científico, sugiriendo en tono irónico una reflexión sobre la legitimidad de los discursos extranjeros. La denuncia parece ser que creemos cualquier cosa que venga de ciertos extranjeros La supuesta ignorancia también es encubierta con el orgullo ignorante que Magón le atribuye. El sentirse orgulloso por tener hijas rubias y blancas es leído por Magón y por sus cómplices lectores como una estupidez, pero Nor Cornelio forma parte de la cultura que reconoce estos atributos como dignos y valorados socialmente. El campesino va más allá y realiza una denuncia que encubre de ingenuidad:

No le niego que a yo se m’hizo cuesta arriba el velas tan canelas y tan gatas, pero dende entonces parece que hubieran traído la bendición de Dios. La mestra me las quiere y les cuece la ropa, el Político les da sus cincos, el Cura me las pide pa pararlas con naguas de puros linoses y antejuelas en el altar pal Corpus y pa los días de la Semana Santa, las sacan en la procesión arrimadas al Nazareno y al Santo Sepulcro; pala Nochebuena las mudan con muy bonitos vestidos y las ponen en el portal junto a las Tres Divinas. Y todos los costos son de bolsa de los mantenedores, y siempre les dan su medio escudo, gu bien su papel de a peso gu otra buena regalía ¡Bendito sea mi Dios que las jue a sacar pa su servicio de un tata tan feo como yo...! (González, 2012, p. 80).

La denuncia consiste en que el reconocimiento por parte de las instituciones centrales en las dinámicas sociales de la época: la educación, la religión y la política, únicamente se da por el fenotipo blanco y rubio de sus hijas. El reconocimiento y la "ayuda" de los grupos hegemónicos al campesino, moreno y tosco, únicamente se dan a partir de sus hijas y sus características físicas. La denuncia cifrada en la supuesta ingenuidad de Nor Cornelio remite a la jerarquización social y al lugar real que se le da al campesino en el Estado-nación. Una pregunta que subyace parece ser: ¿más allá de las sensaciones idílicas y nostálgicas por el campesino, como base imaginaria del nacionalismo costarricense, cuál es el lugar del campesinado en el Estado liberal? Al respecto menciona Amoretti (2000):

Si saber, conocimiento o verdad son los hilos básicos de la red de poder en la sociedad positivo-liberal, el campesino no tiene cabida en ella más que marginalmente; así, erigir al campesino como emblema de lo nacional responde a la mera necesidad de convocar al pueblo para que este se sintiera interpelado por la Nación. (p. 31).

Nor Cornelio reconoce los códigos y los discursos que sobre él se emiten desde la hegemonía, no obstante, su voz subalterna toma el engaño como una estrategia de resistencia, como forma de "revertir sus efectos de poder utilizándolas [a sus hijas] para su beneficio y con apoyo del cuadro institucional o de la autoridad que lo representa, lo cual al mismo tiempo lo invulnera de una posible censura de parte de ese cuadro institucional" (Amoretti, 2000, p. 35). 
La ironía y la complicidad entre autor-narrador y lector refuerza el significado oficial (campesino ignorante, ingenuo; intelectual liberal: sabio, choteador que siempre ejerce poder sobre el campesinado) y con ello se "pone en escena los contenidos de la sustancia ética del poder, sobre la base de los cuales este efectúa sus gestos de exclusión, sus abusos y sus atropellos; es decir, su violencia" (Amoretti, 2000, p. 32).

El juego de miradas que encierra "El clis de sol" produce lugares de tensión entre las voces hegemónicas y las subalternas; las culturas populares que emergen del texto se producen alrededor de los encuentros (y desencuentros) sobre la sabiduría y la ignorancia. La disputa simbólica que encierra el juego de miradas da cuenta de un escenario en disputa, de actores que resisten y no solo asimilan acríticamente. El cuento es en sí mismo un espacio de cultura popular, ya que enfrenta a los grupos hegemónicos y subalternos en lucha simbólica para reelaborar las nociones estereotipadas sobre el Estado liberal, el campesinado y las élites. Las preguntas retóricas de Nor Cornelio siempre ponen en entredicho la sabiduría del otro. A partir de la producción de Magón podemos conocer de la existencia de Nor Cornelio, pero sobre todo de su perspicacia.

$\mathrm{Al}$ igual que en "San José", se puede mencionar que el autor presenta dificultades para descifrar las voces subalternas femeninas, encarnadas en María de los Dolores, María del Pilar y Lina, hijas y esposa de Nor Cornelio. Las voces femeninas aparecen de forma tímida y siempre en función de las disputas masculinas. El engaño de Nor Cornelio da cuenta de masculinidades hegemónicas incapaces de aceptar la infidelidad conyugal, pero a la vez también puede ser interpretado como una forma utilizada por Magón para descolocar a la mujer del papel sumiso, abnegado al hogar y su pareja.

\section{BALANCE FINAL}

A manera de balance se puede mencionar que a pesar de que ambos textos son producidos desde una mirada hegemónica, en ellos se evidencia el sentido ético-histórico en que fueron producidos. Las voces subalternas que aparecen, de forma tímida en "San José" y de forma más contestaria en "El clis de sol", evidencian y denuncian los discursos y las prácticas excluyentes, explotadoras y violentas. Es en esa denuncia, a veces enmascarada de ingenuidad, timidez o ignorancia, que se abren espacios de tensión conformadores de culturas populares. Lugares de tensión donde las disputas materiales y simbólicas ocurren y evidencian realidades complejas mediadas por ejercicios de poder. De esta forma, se produce una ruptura con las aproximaciones categóricas que colocan a las personas y grupos en lugares estáticos.

Amoretti plantea que "el polo" del cual se mofa Magón a finales del siglo XIX, por medio de la adquisición de ciertas características (sabe leer, tiene acceso a publicar), contesta el discurso de "cultura alta". Es ahora él quien se ríe de la 
clase alta. Esto hace pensar en las prácticas y en los discursos que emitían las clases populares, sobre todo el campesinado, sobre las élites. Partiendo de la comprensión del poder como relacional, las prácticas y discursos de las clases populares en la época posiblemente contenían contestaciones y resistencias ante estos discursos, únicamente que las fuentes deben ser leídas de manera detallada.

En este sentido, desde la historia cultural, entendida como historia de las representaciones y las prácticas, la literatura potencia su carácter de fuente primaria, que da cuenta de momentos y sentidos históricos particulares. Se está en frente de dos textos cargados de representaciones sociales, disponibles para ser leídos e interpretados a partir del acervo cultural del profesional en historia.

\section{NOTAS}

1 El presente artículo se desprende de los trabajos finales del curso denominado Taller sobre Problemas, Fuentes y Métodos de la Historia II, impartido por el Dr. David Díaz Arias, en la Maestría de Historia Centroamericana de la Universidad de Costa Rica, II-2013.

2 Entre otros estudios, por ejemplo encontramos los trabajos de Florencia Quesada (1998; 2011); Ofelia Sanou, Florencia Quesada e Ileana Vives (2000); Iván Molina y David Díaz (2008), y Ronald Soto-Quirós (2013).

3 Es importante señalar que Ronald Soto-Quirós (2013a; 2013b) realiza un análisis sobre el uso de las crónicas de viajeros como fuente primaria, enfatizando en las posibilidades que brindan para comprender representaciones y discursos sobre la sociedad, las relaciones sociales y los sujetos, a partir de las nociones eugenésicas y esencialistas sobre el ser costarricense. Por su parte, autoras como Florencia Quesada (1998) no las reconocen abiertamente como fuentes y, por tanto, no plantean una reflexión sobre su uso. Posteriormente, en su trabajo de 2011 sobre el café, Quesada se extiende en su argumentación sobre las crónicas de viaje como una fuente primaria de vital importancia en América Latina, particularmente para el estudio de finales del siglo XIX y principios del siglo XX.

$4 \quad$ Otro ejemplo del uso de literatura como fuente primaria, se puede observar en Molina y Díaz (2008), quienes indagan los imaginarios costarricenses sobre la Campaña Nacional 1856-1857 y su importancia, a partir de la investigación histórica y la creación literaria sobre este evento. Se destaca poesía, novela, drama y cuentos, entre otras producciones literarias.

5 No se cuenta con la información a la mano para determinar con exactitud el tipo de fuente primaria. Se supone la categorización de este texto como crónica literaria o periodística, primero por la formación del escritor (periodista) y segundo porque ya desde inicios de esta era se empleaba el término para referirse a escritos con cierta composición histórica relatada en orden secuencial. Por ejemplo, los monjes entre el siglo V y el XV legaron una cantidad de documentos tipo crónica, escritos todos en latín. Ha habido crónicas desde siglos anteriores. No sería de extrañar que Meagher haya empleado como estilo narratológico este género.

6 Los comentarios que en torno a las ideas de género surjan fueron promovidos tras la lectura de varios textos, a saber: Leonardo Boff y Rose Murano (2004); Emilia Macaya (1997), y Jarami1lo (2007). 


\section{REFERENCIAS}

Aguilar, R. (enero/diciembre, 2005). La guerra centroamericana contra los filibusteros en 1856-1857: Una aproximación a las fuentes bibliográficas y documentales. Revista Historia, (51-52), 463-528.

Alvarenga, P. (julio/octubre, 2003). Historia y literatura. Conceptos tentativos para contribuir a historizar las literaturas centroamericanas. Istmo. Revista Virtual de Estudios Literarios y Culturales Centroamericanos, (6). Recuperado de http://istmo.denison.edu/n06/proyectos/historia.html/

Amoretti, M. (2000). Dos momentos, dos autores en la historia de una literatura. Revista de Filología y Lingüística, 26(2), 27-38. Recuperado de http://revistas.ucr.ac.cr/index.php/filyling/article/ viewFile/4515/4332/

Amoretti, M. (2002). Magón: La irresistible seducción del discurso. Costa Rica: Ediciones Perro Azul.

Boff, L. y Murano, R. (2004). Masculino y femenino. España: Editorial Trotta.

Chartier, R. (1994). Cultura popular: retorno a un concepto historiográfico. Manuscrits, (12), 43-62.

Díaz, D. (2005). Construcción de un Estado moderno: política, Estado e identidad nacional. 18211914. (Serie Cuadernos de Historia de las Instituciones de Costa Rica). Costa Rica: Editorial de la Universidad de Costa Rica.

Enríquez, F. (2001). Control social y diversión pública en Costa Rica (1880 -1930). Diálogos Revista Electrónica de Historia, 2(2). Recuperado de http://revistas.ucr.ac.cr/index.php/dialogos/article/view/6311/6013/

Fernández, R. (1902). Costa Rica en el siglo XIX. Antología de viajeros. Costa Rica: Borrasé.

Fumero, P. (julio/octubre, 2003). Historia y literatura. Una larga y compleja relación. Istmo. Revista Virtual de Estudios Literarios y Culturales Centroamericanos, (6). Recuperado de http://istmo. denison.edu/n06/proyectos/historia2.html/

Goebel, A. (2003). La política económica liberal su rol en el consumo de bienes "monopolizados". El caso del monopolio del tabaco en Costa Rica (1880-1907). Anuario de Estudios Centroamericanos, (29), 147-169.

González, M. (2012 [1896]). El clis de sol. En M. González, Cuentos de Magón (pp-79-81) (1ª ed.). Costa Rica: Imprenta Nacional.

Jaramillo, J. (2007). ¿El sexo débil de la mujer? Costa Rica: Editorial de la Universidad de Costa Rica.

López, B. (2006). Para una tipología del relato de viaje. En B. López y J. Farré (Eds.), Viajes y viajeros. México: Tecnológico de Monterrey. Recuperado de http://www.biblioteca.org.ar/libros/156238.pdf/ 
Macaya, E. (1997). Espíritu en carne altiva. Costa Rica: Editorial de la Universidad de Costa Rica.

Meagher, T. F. (1902). San José. En R. Fernández (Ed.), Costa Rica en el siglo XIX. Antología de viajeros (pp. 333-448). Costa Rica: Borrasé.

Meagher, T. F. (1923). Vacaciones en Costa Rica. Costa Rica: Liceo de Costa Rica.

Menton, S. (1964). El cuento costarricense. México: Ediciones de Andrea.

Molina, I. (2007). Época de profundos cambios: Costa Rica (1821-1849). En I. Molina (Ed.), Industriosa y sobria. Costa Rica en los días de la Campaña Nacional (1856-1857) (pp. 1-28). Estados Unidos: Plumsock Mesoamerican Studies.

Molina, I. y Díaz, D. (2008). Campaña Nacional (1856-1857). Historiografía, literatura y memoria. Costa Rica: Editorial de la Universidad de Costa Rica.

Molina, I. y Fumero, P. (1994). Diversión brillante y útil: documentos para la historia del teatro en la Centroamérica del siglo XIX. Revista de Historia, (29), 211-232.

Obregón, C. (1994). El río San Juan en la lucha de las potencias (1821-1860). Costa Rica: Editorial Universidad Estatal a Distancia.

Quesada, A. (1986). La formación de la narrativa nacional costarricense (1890-1910). Enfoque histórico cultural. Costa Rica: Editorial de la Universidad de Costa Rica.

Quesada, A. (1998). Uno y los otros. Identidad y literatura en Costa Rica (1890-1940). Costa Rica: Editorial de la Universidad de Costa Rica.

Quesada, A. (2008). Breve historia de la literatura costarricense. Costa Rica: Editorial de la Universidad de Costa Rica.

Quesada, F. (1998). La vida interior y exterior de Barrio Amón. Arquitectura, familia y sociabilidad burguesa en la capital costarricense 1900-1935. (Tesis de Maestría en Historia). Universidad de Costa Rica, Costa Rica.

Quesada, F. (2011). La modernización entre cafetales. San José, Costa Rica, 1880-1930. Costa Rica: Editorial de la Universidad de Costa Rica.

Sanou, O., Quesada, F. y Vives, I. (2000). La arquitectura de las haciendas cañeras y cafetaleras de la región Reventazón-Turrialba: lo local, los inmigrantes y el medio ambiente (Informe No. 80698-373). Costa Rica: Centro de Investigaciones Históricas de América Central.

Silva, M. (1989). La educación de la mujer en Costa Rica durante el siglo XIX. Revista de Historia, (20). Recuperado de http://www.revistas.una.ac.cr/index.php/historia/article/view/3265/

Soto-Quirós, R. (2013a). Viajeros, traducciones y autoelogios: el interés por los relatos de extranjeros, Costa Rica, 1871-1944. Boletín AFEHC, (56). Recuperado de http://afehc-historia-centroamericana.org/index.php?action=fi_aff\&id=3503/ 
Soto-Quirós, R. (2013b). "Whiteness studies" y relatos de viajeros: los costarricenses en las miradas anglosajonas (1844-1868). Boletín AFEHC, (57). Recuperado de http://afehc-historia-centroamericana.org/index.php?action=fi_aff\&id=3592/

Sistema Nacional de Bibliotecas. (s.f.). González Zeledón, Manuel "Magón”. Diccionario biográfico. Recuperado de http://www.sinabi.go.cr/DiccionarioBiograficoDetail/biografia/148/ 